\title{
Impact of Selected Macroeconomic Variables on Stock Market in India
}

\author{
Debasish Sur ${ }^{1}$, Amalendu Bhunia ${ }^{2}$ \\ ${ }^{1}$ Department of Commerce, the University of Burdwan, West Bengal, India \\ ${ }^{2}$ Department of Commerce, University of Kalyani, Kalyani, Nadia, West Bengal, India
}

Email address:

debasishsur@yahoo.co.in (D. Sur), bhunia.amalendu@gmail.com (A. Bhunia)

\section{To cite this article:}

Debasish Sur, Amalendu Bhunia. Impact of Selected Macroeconomic Variables on Stock Market in India. American Journal of Theoretical and Applied Business. Vol. 1, No. 3, 2015, pp. 53-63. doi: 10.11648/j.ajtab.20150103.11

\begin{abstract}
Purpose of the study: The present study investigates the influence of selected macroeconomic variables in terms of international crude oil price, exchange rates, domestic gold price, real interest rates and wholesale price index on stock market indices (sensex and nifty) of India. Background: Macroeconomic variables directly or indirectly affect the stock prices because it influences strongly the stock returns by affecting the stock prices, which supports the existance of a long-run relationship between the macroeconomic variables and stock prices. Methodology: This study is based on time series monthly data collected from Reserve Bank of India database; BSE and NSE database, investing.com and yahoo, finance database for the period July 1997 to July 2015 with the application of financial econometrics. Results: The empirical results reveal that sensex and nifty reactions to shocks on crude oil prices, exchanges rates, real interest rates and whole prices indices were positive while a negative shock from sensex and nifty to real interest was noticed.
\end{abstract}

Keywords: Macroeconomic Indicators, Stock Market, India, Cointegration Test, Causality Test, Vector Error Correction Model

\section{Introduction}

The hot and flowing questions in the stock market study are whether the macroeconomic variables unswervingly or not directly influence the stock prices. On this topic, academicians, professionals and proficient finance experts are harshly alienated into two schools of consideration. One school of consideration believes macroeconomic variables just as immaterial to the stock prices. In this context, the Efficient Market Hypothesis (Fama, 1965, Fama, 1970) states that in an efficient market all the relevant information about the volatility in macroeconomic variables are fully reflected in the current stock prices and thus, in such market abnormal profits cannot be earned by the investors regardless of their investment strategies. The other school of consideration speaks out that macroeconomic variables persuade sturdily the stock returns by influencing stock prices. In this context, the Arbitrage Pricing Theory (Ross, 1976, Chen et al, 1986) supports the existance of a long-run relationship between the macroeconomic variables and stock prices. According to this theory, the investors can predict the future stock prices by analying the trends in macroeconomic variables and hence, with the help of such prediction they can earn abnormal profits. So, debate silently continues. In the midst of the prominent change in the economic obverse ever since 1991 owing to approval of liberalization measures, together with erstwhile supports of Indian financial system the capital market in India has furthermore transformed extensively bringing about perceptible changes in the environment of its accomplices. In fact, the foreign institutional as well as individual investors have got an easy access to the Indian stock market. In this milieu, this study endeavours to investigate the association between the macroeconomic variables and and stock prices during the period July 1997 to July 2015.

\section{Review of Related Literature}

Prior to setting the goals of a study it is obligatory to review the existing literature on the issue connected with the investigation as well as to determine the research gaps. The subsequent parts in this section presents a brief description of some of the notable studies carried out in the last few decades in India on the topic addressed in the present study and the final snippet in this section handles the recognition of the research gaps. 
Krugman (1983) in his study examined the short run and long run effects of oil price shocks in three selected countries, such as OPEC, Germany and U.S.A applying partial equilibrium balance of payment model. The study revealed that oil price shocks affected significantly two major variables, namely export and exchange rate in all the three selected countries during the study period. Chen et al (1986) in their study investigated the interrelationship between macroeconomic variables and stock market returns in U.S.A for the period from January 1953 to November 1983. While carrying out the study, vector autoregressive model was used. The study observed that the stock market returns in U.S.A were exposed to systematic economic news. The study also found that inflation, industrial production, spread between long term and short term interest rates and spread between high and low grade bonds affected systematically stock market returns. Barrows and Nakat (1994) in their study assessed the impact of the selected macroeconomic variables such as money supply, expected inflation rate, term structure of interest rate, domestic consumption and industrial production on the stock returns of the companies belonging to the hotel industry in U.S.A. The net outcome derived from the multiple regression analysis as made in the study indicated that the direction of macroeconomic forces was consistent across the industry. The study also concluded that the macroeconomic variables explained the movement of stock returns in the restaurant sector to a greater extent as compared to that in the lodging sector. Kwon and Shin (1999) in their study examined whether the Korean economic activities influenced the stock returns during the period from January 1980 to December 1992. The Johansen cointegration test, pairwise Granger causality test and vector error correction model were used in this study. The study observed that the Korean stock price index were cointegrated with the macroeconomic variables such as exchange rate, money supply, production index and foreign trade balance and each stock price index. The study also revealed that notable influence of the selected macroeconomic variables on the Korean stock market was found in the short run. In the study carried out by Omran and Pointon (2001), the impact of inflation rate on the stock market performance in Egypt for the period from 1980 to 1998 was assessed using the co-integration test and error correction model. The study revealed that strong evidence of the impact of inflation rate on the Egyptian stock market performance was noticed during the period under study. Apergis and Eleftheriou (2002) in their study attempted to investigate the relationship among inflation rate, interest rate and stock prices in Greece during the period 1988 to 1999 . The study observed that the relationship between inflation rate and stock prices was stronger as compared to that between interest rate and stock prices in most of the times under study. Bhattacharya and Mukherjee (2002) in their study attempted to analyse the causal relationships between the BSE Sensex and the five selected macroeconomic variables based on the monthly data from April 1992 to March 2001 using unit root test, cointegration test and long-term causality test. The study revealed that no causal relationship between stock prices and money supply, that between stock prices and national income or that between stock prices and interest rate was present while index of industrial production influenced significantly the stock prices. The study also found bidirectional causation between stock price and inflation rate during the study period. Mishra (2004) considering the period from April 1992 to March 2002 conducted a study in the Indian context in which the objectives and methodology were almost similar to those as used in the study made by Kwon and Shin (1999). The study revealed Granger causality between the exchange rate fluctuation and stock return during the study period. The study also observed that stock return, exchange rate return, demand for money and interest rate were associated with each other while such associations were not at all consistent. Cong et al (2008) in their study by considering the monthly data from January 1996 to December 2007 examined the relationships between oil price shocks and Chinese stock market applying multivariate autoregressive method. The study divulged that no strong evidence of the impact of oil price shocks on the real stock returns of most of the stock market indices in China was noticed. In the study made by Panda (2008), by using the monthly averages of the Sensex and Nifty as stock price indicators and the month-end yields on 10-year government security and treasury bills (91 days) as measures of long term and short term interest rates for the period from April 1996 to June 2006, the influence of interest rate on Indian stock markets was assessed. The study observed strong evidence of negative association between the long term interest rates and stock prices whereas the positive influence of short term interest rates on stock prices was noticed during the study period. The study also found that the Sensex was more responsive to changes in interest rates as compared to the Nifty during the period under study. Sahu and Gupta (2011) conducted a study for investigating the relationship between inflation and stock return in the Indian stock market. In this study the researchers used the weekly data for the period from July 2006 to October 2009 and also applied Event Study Methodology. The study revealed that in most of the cases a significant negative association between the inflation rate and the stock return during the study period was noticed. Naik and Padhi (2012) in their study investigated the relationships between the Indian stock market index (BSE Sensex) and five selected macroeconomic variables, that is to say, industrial production indices, wholesale price index, money supply, treasury bills rates and exchange rates over the period from April 1994 to June 2011. Johansen's co-integration and vector error correction model were used to investigate the long-term stability association between stock market index and macroeconomic variables. The analysis divulged that macroeconomic variables and the stock market index were co-integrated and, hence, a long-run equilibrium relationship existed between them. The study also observed that the stock prices were positively associated with the money supply and industrial production but negatively related to inflation. The exchange rate and the short-term interest rate were found to be irrelevant in assessing stock prices. In the Granger 
causality sense, macroeconomic variables caused the stock prices in the long-run only. Bidirectional causality between industrial production and stock prices were observed whereas unidirectional causality from money supply to stock price, stock price to inflation and interest rates to stock prices were found. The study made by Abdelbaki (2013) examined the nature and extent of relationship between macroeconomic variables and Bahraini stock market development for the period 1990 to 2007 . The study revealed that Bahraini stock market development was highly influenced by the level of income, domestic investment, private capital flows and stock market liquidity during the period under study.

A large number of studies have been carried out on the analysis of the relationship between the macroeconomic variables and stock price movement. The most of the significant studies so far conducted in this domain are associated with developed economies. In India the issue has not been addressed with due importance. A very few studies have so far been carried out in India on this topic. Moreover, there has been a notable disparity in the variable selection as well as the methodologies adopted to deal with the matter in the studies as made in both India and abroad. Therefore, the outcomes derived from the studies on the topic are contradictory in nature and the studies have not been able to provide any definite conclusion. So, the issue is still unresolved especially in developing countries like India. In order to bridge the gap the present study was made.

\section{Material and Methods}

\subsection{Data Source}

The monthly time series data for the period from July 1997 to July 2015 which were used in the present study were collected from Reserve Bank of India database; BSE and NSE database, investing.com and yahoo finance database. In this study July 1997 was taken as the initial point of the study period. The research work starts on July 1997 (Patel, 2014; Tripathi and Seth, 2014) because Indian stock market was affected due to Asian crsis, on one side and the ease of use of the most recent availability of published time series data, on another side.

\subsection{Sample Selection}

In this study five macroeconomic variables, for example, International crude oil price (COP), Domestic gold price (GP), Rupee-dollar exchange rates (ER), Real interest rates (RIR) and Wholesale price indices (WPI) were considered as explanatory variables while two extensively exercised composite indices of the stock market of India, namely Sensex and Nifty were taken into consideration as dependent ones. Prior to starting investigation in this study the monthly data were converted into natural logarithm for keeping the data normal as well as for reducing the problem of heteroskedasticity. The empirical results were obtained using SPSS 19 and Eviews 9 softwares.

\subsection{Variables Description}

\subsubsection{Crude Oil Price}

Crude oil has turn out to be one of significant commodities by reason of its excellent significance in the supply of the world's energy needs. Usually India relies on imports of crude oil (India presently imports about 80 per cent of its need) from other countries because the country does not have enough oil reserves. By and large crude oil imports augment the import bill too if Indian rupee is depreciated significantly. As a result, it enhances the current account deficit and ultimately hit the inflation rate. In consequence of high inflation public spend more in gold and less in stocks reasoning the stock markets to fall. At the same time, augment in oil prices will elevate input costs of businesses which ultimately decrease the business earnings. Again, when corporate earnings are reduced due to rise of crude oil price, stock market might be decreased.

\subsubsection{Gold Price}

Gold has become one of significant commodities as a secured investment for investor in India and investors generally outlook as rates of inflation thwart. Gold prices are concerned by way of demand and supply of gold, RBI policies regarding gold, widespread social situations, act of substitute assets, for instance, US dollar, bonds and equities; rates of interest rates and inflation rates. In times of crisis, if the future prospects of the economy are shocking, then investors sprint to the safe haven gold and affect the stock market (Bhunia and Mukhuti, 2013).

\subsubsection{Exchange Rates}

Exchange rate in terms of rupee-dollar exchange rates is one of the vital indicator during which a country's economic health is established. By and large exchange rates are persuaded by inflation rates, interest rates, country's current account, government debt, and terms of trade, political stability, downturn and conjecture. Exchange rates rise and fall shocks the firms' competitiveness that influences the company's earnings and the funds cost. Yet again depreciation of rupee fashions the lure of the exporting goods and brings about a raise in foreign demand and firms' revenue that ultimately affect the stock market.

\subsubsection{Real Interest Rates}

Inflation adjusted interest rate or real interest rate is one of the important macroeconomic indicators in any economy because it signifies the real cost of lending and change the behavior of the individual and businesses. When interest rates are increased on company borrowings, it increases the cash flows and decreases the company's earnings. In this situation, investors withdraws amount from the stock market and consequently affect the stock market indexes.

\subsubsection{Wholesale Price Index}

The wholesale price index is another important macroeconomic variable which provides a signal of price movements in all markets of a country more willingly than retail markets. It is the chief measure of inflation in India. WPI influences companies or dealers profits while they act massive 
buying. However, price movements influence the expectations of investors as well as companies earnings which affect the stock market.

\subsubsection{Sensex}

Sensex is a leading index because it shows the situation of the market and the overall economic situation of the country. At the same time, it signifies the major and most impressive companies in India. For that reason, sensex is considered as most important economic indicator since it reveals what is going to occur in the economy at some point.

\subsubsection{Nifty}

Nifty index is not merely a leading index however it is an indicator of the flourishing Indian economy. In spite of the current decelerate in the economic outlook the Nifty index has maintained a usual development after conquering the unexpected shock. This index has fascinated investors not merely from the domestic market however also from foreign countries. Therefore, nifty is considered as most important economic indicator because it points out what is going to take place in the economy at some point.

\subsection{Tools Used}

While analyzing the data descriptive statistics, correlation statistics and econometric tools like Augmented Dickey Fuller both at levels and 1st differences and Johansen cointegration test were applied at appropriate places.

\section{Empirical Results and Analysis}

\subsection{Descriptive Statistics}

To make an explanation about time series data more unambiguous as well as faultless, the descriptive statistics have been worked out from the natural log values of sensex (lsx), nifty (lnfty), gold price (lgp), international crude oil price (lcop), dollar-rupee exchange rates (ler), wholesale price index (lwpi) and real interest rates (lrir). Descriptive statistics signifies that mean and standard deviation alters with time and none of the selected series are normally distributed that has been presented in table 1 .

Table 1. Descriptive Statistics.

\begin{tabular}{llllllll}
\hline & lcop & ler & lgp & lnfty & Irir & Isx & Iwpi \\
\hline Mean & 3.88981 & 3.87231 & 6.42996 & 2.20412 & 2.105116 & 9.09381 & 4.896833 \\
Median & 4.06790 & 3.83789 & 6.445777 & 2.221860 & 2.074178 & 9.22449 & 4.869839 \\
Maximum & 4.94164 & 4.18517 & 7.511251 & 2.330454 & 2.509762 & 10.2826 & 5.225209 \\
Minimum & 2.41769 & 3.66854 & 5.544396 & 2.072061 & 1.629241 & 7.94117 & 3.561046 \\
Std. Dev. & 0.63414 & 0.12240 & 0.662573 & 0.083803 & 0.220383 & 0.75583 & 0.221334 \\
Skewness & -0.44484 & 0.86881 & 0.116989 & -0.162512 & 0.153289 & -0.10962 & -1.852850 \\
Kurtosis & 1.99247 & 2.93217 & 1.446214 & 1.443830 & 2.769451 & 1.44134 & 13.18338 \\
Jarque-Bera & 16.2585 & 27.2154 & 22.22098 & 22.74576 & 1.324291 & 22.2972 & 1056.901 \\
Probability & 0.00029 & 0.0000 & 0.000015 & 0.000012 & 0.515744 & 0.00001 & 0.000000 \\
Observations & 216 & 216 & 216 & 216 & 216 & 216 & 216 \\
\hline
\end{tabular}

\subsection{Correlation Statistics}

To build an investigation the association between macroeconomic variables and stock markets (sensex and nifty), the correlation statistics have been worked out from the natural log values of all the selected series that has been presented in table 2 . The results of the correlation statistics disclosed that crude oil price, gold price, exchange rates and wholesale price index are positively related with sensex and nifty but real interest rates have exposed negative correlation with sensex and nifty which is significant at 1 per cent level.

Table 2. Correlation Statistics.

\begin{tabular}{|c|c|c|c|c|c|c|c|}
\hline & lcop & $\lg p$ & ler & Irir & Iwpi & Isx & Infty \\
\hline lcop & 1 & & & & & & \\
\hline \multirow[t]{2}{*}{$\operatorname{lgp}$} & $.883 * *$ & 1 & & & & & \\
\hline & .000 & & & & & & \\
\hline \multirow[t]{2}{*}{ ler } & $.473 * *$ & $.607 * *$ & 1 & & & & \\
\hline & .000 & .000 & & & & & \\
\hline \multirow[t]{2}{*}{ lrir } & $-.369 * *$ & $-.249 * *$ & .014 & 1 & & & \\
\hline & .000 & .000 & .837 & & & & \\
\hline lwpi & .000 & .000 & .000 & .000 & & & \\
\hline \multirow[t]{2}{*}{ lsx } & $.898 * *$ & $.937 * *$ & $.577 * *$ & $-.207 * *$ & $.387 * *$ & 1 & \\
\hline & .000 & .000 & .000 & .002 & .000 & & \\
\hline \multirow[t]{2}{*}{$\operatorname{lnfty}$} & $.904 * *$ & $.936 * *$ & $.563 * *$ & $-.215^{* *}$ & $.380 * *$ & $0.997 * *$ & 1 \\
\hline & .000 & .000 & .000 & .002 & .000 & .000 & \\
\hline
\end{tabular}

** Correlation is significant at the 0.01 level (2-tailed). 


\subsection{Optimum Lag Length Selection}

The lag length selection of $p$ that should be included in the test regression models of ADF test and VECM test because it is one of the vital realistic problems for the performance of ADF unit root test cointegration test and causality test. So lag length selection is not an insignificant job. If $\mathrm{p}$ is excessively small at that time the residual serial correlation in the errors will prejudice the test and when $p$ is excessively huge at that moment the power of the test will undergo. The wide-ranging approach is to robust models with values of $\mathrm{pK} 0=\max \mathrm{p}$ and subsequently to choose the value of $\mathrm{p}$ to minimize a few model choice criterions. The three most extensively utilized information criteria are the Akaike Information Criterion (AIC), the Schwarz-Bayesian Criterion (BIC) and the Hannan-Quinn Criterion (HQC). For selection of optimum lag length maximum lag order 5 has been considered. The results are tabulated in the following table.

The asterisks below indicate the best (that is, minimized) values of the respective information criteria, $\mathrm{AIC}=$ Akaike criterion, $\mathrm{BIC}=$ Schwarz Bayesian criterion and $\mathrm{HQC}=$ Hannan-Quinn criterion.

Table 3. Optimum VAR Lag Length Test Results.

\begin{tabular}{llllll}
\hline lags & loglik & $\mathbf{p}(\mathbf{L R})$ & AIC & BIC & HQC \\
\hline 1 & 1543.68206 & & $-\mathbf{1 4 . 4 8 0 3 9 9 *}$ & $-14.226229^{*}$ & $-14.377658^{*}$ \\
2 & 1544.02670 & 0.95265 & -14.445751 & -14.128039 & -14.317325 \\
3 & 1546.66524 & 0.26003 & -14.432846 & -14.051592 & -14.278735 \\
4 & 1548.74508 & 0.38483 & -14.414645 & -13.969849 & -14.234850 \\
5 & 1550.67921 & 0.42413 & -14.395064 & -13.886725 & -14.189583 \\
\hline
\end{tabular}

\subsection{Unit Root Test Results}

In the midst of underlying principle of the test of stationarity, Augmented Dickey-Fuller unit root test technique is used through the levels and first differences of all the series under the study covering the stipulation so that the null hypothesis is stationary, accordingly buoyant response of the unit root hypothesis maintains stationarity. ADF unit root test results based on AIC are exposed in table 4 and illustrate that the LSX, LGP, LCOP, LER, LWPI, LRIR and LNFTY are not stationary at level but stationary at 1 st difference.

Table 4. ADF Unit Root Test Result.

\begin{tabular}{lll}
\hline & At level & At $\mathbf{1}^{\text {st }}$ Difference \\
\hline lsx & -1.090364 (Non-stationary) & -13.86328 (Stationary) \\
lgp & -0.461857 (Non-stationary) & -16.74626 (Stationary) \\
lcop & -0.835588 (Non-stationary) & -13.15422 (Stationary) \\
ler & -2.194010 (Non-stationary) & -12.86623 (Stationary) \\
lwpi & -1.657123 (Non-Stationary) & -16.69276 (Stationary) \\
lrir & -0.805742 (Non-stationary) & -8.873557 (Stationary) \\
lnfty & -1.030533 (Non-stationary) & -13.93940 (Stationary) \\
Critical Values & & \\
$1 \%$ level & -3.460739 & -3.460739 \\
$5 \%$ level & -2.874804 & -2.874804 \\
$10 \%$ level & -2.573917 & -2.573917 \\
\hline
\end{tabular}

\subsection{Cointegration Test Results}

To test the long-run association among the selected variables under the study, multivariate cointegration test method in Johansen approach is suitable. While all the selected variables are stationary, long-run association can straightforwardly be confirmed by employing cointegration test method. In this research effort, linear deterministic trend has been presumed to work out how these deterministic factors are actually included in the depictions. In this test, lag length 1 has been based on Akaike Information Criterion
(AIC). A critical value of Osterwald-Lenum (1992) at 5 percent level has been considered for this test. Moreover, an additional resourceful inference method of the deterministic factors have been considered on the condition that the linear trend can be alleged to be at largely linear and not quadratic, as supported in, (Luutkepohl and Saikkonen, 2000).

Table 5. Johansen Cointegration Test Result (Lag Length - 1***).

\begin{tabular}{|c|c|c|c|c|}
\hline \multicolumn{5}{|c|}{ Unrestricted Cointegration Rank Test (Trace) } \\
\hline \multirow{2}{*}{$\begin{array}{l}\text { Null } \\
\text { Hypothesis }\end{array}$} & Trace* & $0.05 * *$ & Max-Eigen* & $0.05^{* * *}$ \\
\hline & Statistic & $\begin{array}{l}\text { Critical } \\
\text { Value }\end{array}$ & Statistic & $\begin{array}{l}\text { Critical } \\
\text { Value }\end{array}$ \\
\hline$r \leq 0$ & 184.75 & 125.62 & 106.89 & 46.23 \\
\hline$r \leq 1$ & 77.86 & 95.75 & 28.73 & 40.08 \\
\hline$r \leq 2$ & 49.13 & 69.82 & 20.68 & 33.88 \\
\hline$r \leq 3$ & 28.45 & 47.86 & 13.62 & 27.58 \\
\hline$r \leq 4$ & 14.83 & 29.80 & 8.71 & 21.13 \\
\hline$r \leq 5$ & 6.12 & 15.49 & 5.48 & 14.26 \\
\hline$r \leq 6$ & 0.64 & 3.84 & 0.64 & 3.84 \\
\hline
\end{tabular}

*Trace test and max-eigenvalue test indicates 1 cointegratingeqn(s) at the 0.05 level

***ritical values obtained from Osterwald-Lenum (1992)

***Lag length based on Akaike Information Criterion (AIC)

The results of cointegration test have been exposed in table 5. Two likelihood ratios of the maximum-eigen value statistics and the trace statistics have been considered here. Table 5 illustrates the results of cointegration test and confirms that both the test statistics is more than its critical value while $r \leq 0$, which indicates there is a petite long-run association among the selected variables exists as supported in, Wang et al (2010) and Hussin et al (2013). Accordingly, this result will release the enormous space for investors to spread their portfolios fearlessly. 


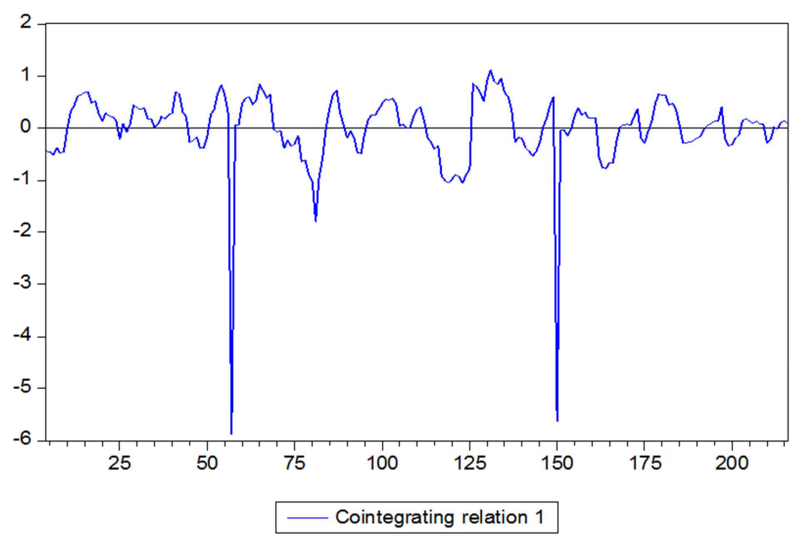

Fig. 1. Cointegration Relationships among Selected Variables.

\subsection{VECM Test Results}

The multivariate cointegration test results for macroeconomic indicators of crude oil price, exchange rates, gold price, real interest rates and wholesale price index and the two stock market index of sensex and nifty using unrestricted vector autocorrelation model for long-run association were not supported. For that reason, Vector Error Correction (VECM) Model based on AIC with lag length 1 for this model and lags 2 for the residuals of the model so that it is free from autocorrelation was used for getting better results. The consequence and extent of the coefficients on the cointegrating equation confined the reaction of each variable in the macroeconomic set to exit from the long-term relationship. The test results indicate that sensex and nifty accept disorders to reinstate long-run relationship. However, those macroeconomic variables did not respond considerably. But sensex regulated more quickly to shocks in reverse way as compared to nifty. The reverse signals reflect a positive long-run relationship between sensex and macroeconomic variables as well as between nifty and macroeconomic variables. Short-run relations were exposed by the coefficients on the lagged differenced terms which conform to the outcome of the study carried out by Gilmore et al, 2009.

Table 6. VECM Test Result.

\begin{tabular}{|c|c|c|c|c|c|c|c|}
\hline Error Correction: & D(LCOP) & D(LER) & D(LGP) & D(LNFTY) & D(LRIR) & D(LSX) & D(LWPI) \\
\hline \multirow[t]{3}{*}{ CointEq1 } & -0.011226 & 0.004735 & 0.010494 & 0.000575 & -0.013534 & 0.004585 & -0.119683 \\
\hline & $(0.01241)$ & $(0.0027)$ & $(0.0065)$ & $(0.0011)$ & $(0.00545)$ & $(0.00966)$ & $(0.0211)$ \\
\hline & {$[-0.9046]$} & {$[1.7734]$} & [1.6274] & {$[0.5279]$} & {$[-2.4815]$} & {$[0.4746]$} & {$[-5.6739]$} \\
\hline \multirow[t]{3}{*}{$\mathrm{D}(\operatorname{LCOP}(-1))$} & 0.086008 & -0.014058 & -0.075363 & 0.010797 & 0.037352 & 0.090016 & 0.298777 \\
\hline & $(0.08030)$ & $(0.0173)$ & $(0.0417)$ & $(0.0071)$ & $(0.03529)$ & $(0.06252)$ & $(0.1365)$ \\
\hline & [1.07108] & {$[-0.8136]$} & {$[-1.8061]$} & {$[1.5316]$} & [1.05835] & [1.43985] & [2.1889] \\
\hline \multirow[t]{3}{*}{$\mathrm{D}(\operatorname{LCOP}(-2))$} & -0.007055 & 0.004659 & -0.030367 & $-6.46 \mathrm{E}-05$ & -0.010884 & -0.003339 & 0.138993 \\
\hline & $(0.07718)$ & $(0.0166)$ & $(0.0401)$ & $(0.0068)$ & $(0.03392)$ & $(0.06009)$ & $(0.1312)$ \\
\hline & {$[-0.09141]$} & {$[0.2805]$} & {$[-0.7572]$} & {$[-0.0095]$} & {$[-0.32086]$} & {$[-0.05557]$} & {$[1.0595]$} \\
\hline \multirow[t]{3}{*}{ D(LER(-1)) } & 0.217524 & 0.204789 & 0.276693 & 0.057934 & -0.004952 & 0.553280 & -1.352261 \\
\hline & $(0.33039)$ & $(0.0711)$ & $(0.1717)$ & $(0.0290)$ & $(0.14521)$ & $(0.25722)$ & $(0.5616)$ \\
\hline & {$[0.6584]$} & {$[2.8806]$} & {$[1.6116]$} & [1.9975] & {$[-0.03410]$} & [2.15099] & {$[-2.4078]$} \\
\hline \multirow[t]{3}{*}{$\mathrm{D}(\operatorname{LER}(-2))$} & -0.220450 & -0.042307 & -0.260222 & -0.042202 & -0.039331 & -0.384467 & -0.462768 \\
\hline & $(0.33620)$ & $(0.0723)$ & $(0.1747)$ & $(0.0295)$ & $(0.14776)$ & $(0.26174)$ & $(0.5715)$ \\
\hline & {$[-0.65572]$} & {$[-0.5848]$} & {$[-1.4895]$} & [-1.4299] & {$[-0.26618]$} & [-1.46887] & {$[-0.8098]$} \\
\hline \multirow[t]{3}{*}{$\mathrm{D}(\operatorname{LGP}(-1))$} & -0.016357 & -0.028247 & -0.107924 & 0.000394 & -0.119540 & -0.004155 & 0.514633 \\
\hline & $(0.13507)$ & $(0.0291)$ & $(0.0702)$ & $(0.0119)$ & $(0.05936)$ & $(0.10516)$ & $(0.2296)$ \\
\hline & {$[-0.12110]$} & [-0.9719] & {$[-1.5376]$} & [0.0332] & {$[-2.01369]$} & {$[-0.03951]$} & [2.2414] \\
\hline \multirow[t]{3}{*}{$\mathrm{D}(\operatorname{LGP}(-2))$} & -0.253131 & 0.058213 & -0.099119 & 0.007491 & -0.060686 & 0.069822 & -0.231422 \\
\hline & $(0.13691)$ & $(0.0294)$ & $(0.0711)$ & $(0.0120)$ & $(0.06017)$ & $(0.10659)$ & $(0.2327)$ \\
\hline & {$[-1.84887]$} & [1.9759] & {$[-1.3932]$} & {$[0.6232]$} & {$[-1.00851]$} & {$[0.65504]$} & {$[-0.9944]$} \\
\hline \multirow[t]{3}{*}{ D(LNFTY(-1)) } & -4.617877 & 1.533598 & 7.800421 & -0.526811 & -0.860830 & -4.420173 & 27.83957 \\
\hline & $(10.5136)$ & $(2.2623)$ & $(5.4633)$ & $(0.9229)$ & $(4.62078)$ & $(8.18529)$ & $(17.872)$ \\
\hline & {$[-0.43923]$} & {$[0.6770]$} & [1.4278] & {$[-0.5700]$} & {$[-0.18630]$} & {$[-0.54001]$} & [1.5576] \\
\hline \multirow[t]{3}{*}{ D(LNFTY(-2)) } & -12.76121 & 0.298605 & -4.389192 & 0.942522 & -2.506605 & 7.969100 & 3.703942 \\
\hline & (10.4972) & $(2.2585)$ & $(5.4542)$ & $(0.9210)$ & $(4.61358)$ & $(8.17255)$ & (17.848) \\
\hline & {$[-1.21567]$} & {$[0.1320]$} & {$[-0.8045]$} & [1.0221] & {$[-0.54331]$} & {$[0.97511]$} & [0.2078] \\
\hline \multirow[t]{3}{*}{ D(LRIR(-1)) } & 0.401927 & 0.000428 & 0.061749 & 0.003994 & -0.058787 & 0.052871 & -0.260404 \\
\hline & $(0.16797)$ & $(0.0364)$ & $(0.0878)$ & $(0.0145)$ & $(0.07382)$ & $(0.13077)$ & $(0.2852)$ \\
\hline & [2.39286] & [0.0118] & [0.7074] & [0.2709] & {$[-0.79632]$} & [0.40430] & {$[-0.912]$} \\
\hline \multirow[t]{3}{*}{ D(LRIR(-2)) } & 0.485804 & -0.001156 & 0.384665 & 0.030128 & 0.164459 & 0.280388 & 0.150440 \\
\hline & $(0.16756)$ & $(0.036)$ & $(0.087)$ & $(0.0147)$ & $(0.07364)$ & $(0.13045)$ & $(0.2848)$ \\
\hline & [2.8993] & {$[-0.0321]$} & [4.4179] & [2.0482] & [2.2332] & [2.1494] & {$[0.5282]$} \\
\hline \multirow[t]{3}{*}{$\mathrm{D}(\operatorname{LSX}(-1))$} & 0.325487 & -0.192031 & -0.861559 & 0.058008 & 0.124897 & 0.493427 & -3.296339 \\
\hline & (1.18446) & $(0.2549)$ & $(0.6155)$ & $(0.1039)$ & $(0.52058)$ & $(0.92216)$ & (2.0134) \\
\hline & [0.2748] & {$[-0.7534]$} & {$[-1.3998]$} & [0.5579] & [0.23992] & {$[0.53508]$} & {$[-1.6372]$} \\
\hline $\mathrm{D}(\operatorname{LSX}(-2))$ & 1.584637 & -0.042349 & 0.583455 & -0.093740 & 0.380164 & -0.793949 & -0.103580 \\
\hline
\end{tabular}




\begin{tabular}{llllllll}
\hline Error Correction: & D(LCOP) & D(LER) & D(LGP) & D(LNFTY) & D(LRIR) & D(LSX) & D(LWPI) \\
\hline & $(1.18194)$ & $(0.2543)$ & $(0.6142)$ & $(0.1038)$ & $(0.51947)$ & $(0.92019)$ & $(2.0091)$ \\
& {$[1.3407]$} & {$[-0.1665]$} & {$[0.9499]$} & {$[-0.9035]$} & {$[0.73183]$} & {$[-0.86281]$} & {$[-0.0515]$} \\
D(LWPI(-1)) & 0.005564 & -0.004834 & -0.036926 & -0.002173 & 0.037556 & -0.014355 & -0.297363 \\
& $(0.04969)$ & $(0.0107)$ & $(0.0258)$ & $(0.0044)$ & $(0.02184)$ & $(0.03868)$ & $(0.0845)$ \\
& {$[0.11199]$} & {$[-0.4521]$} & {$[-1.4301]$} & {$[-0.4982]$} & {$[1.71973]$} & {$[-0.37108]$} & {$[-3.5206]$} \\
D(LWPI(-2)) & 0.010019 & -0.018200 & -0.038168 & -0.001784 & 0.000264 & -0.015668 & -0.087338 \\
& $(0.04114)$ & $(0.0088)$ & $(0.0214)$ & $(0.0036)$ & $(0.01808)$ & $(0.03203)$ & $(0.0699)$ \\
& {$[0.24352]$} & {$[-2.0558]$} & {$[-1.7852]$} & {$[-0.4938]$} & {$[0.0146]$} & {$[-0.4891]$} & {$[-1.2488]$} \\
\hline
\end{tabular}

Included observations: 213 after adjustments; Standard errors in ( ) \& t-statistics in [ ]

\subsection{Impulse Response Test Figures}

Impulse response purposes elucidate how every variable reacts to shocks by other variables in addition to therefore give further approaching into the interdependence between the variables. Impulse response assesses the vibrant result on each variable from a one standard deviation shock to every variable. There is a smaller extent of interdependence or a larger extent of independence between the variables if reactions to shocks are petite and are not constant over time. The above figure presents the impulse response graphs for the selected variables. The graphs on the first row signify the reactions by the crude oil price to shocks from each of the other selected variables under study at the same time as the graphs on the first column indicate the reactions of other variables to shocks from crude oil price. In the same way, the graphs on the second row stand for the responses by the exchange rates, to a shock from other selected variables whereas the graphs on the second column stand for the reactions of other selected variables series to a shock from exchange rates. Again, the graphs on the fourth row stand for the responses by the nifty, to a shock from other selected variables whereas the graphs on the fourth column stand for the reactions of other selected variables series to a shock from nifty. However, the graphs on the sixth row stand for the responses by the sensex, to a shock from other selected variables but the graphs on the sixth column stand for the reactions of other selected variables series to a shock from sensex, and so on. For all graphs, the vertical axis shows the estimated one hundredth point change in the variables by reason of an one-standard deviation shock in a specified endogenous variables under study and the horizontal axis illustrates the reactions up to 12 months.
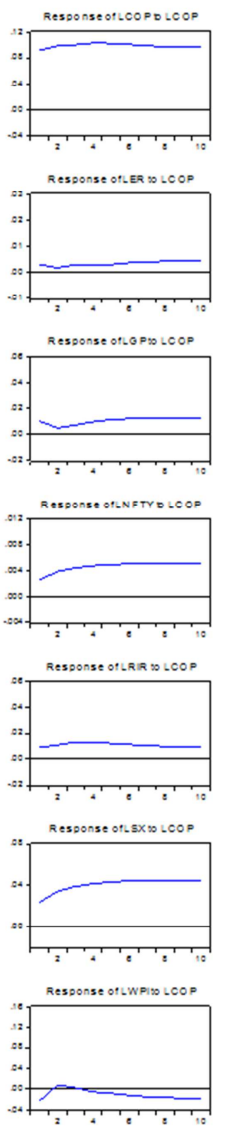
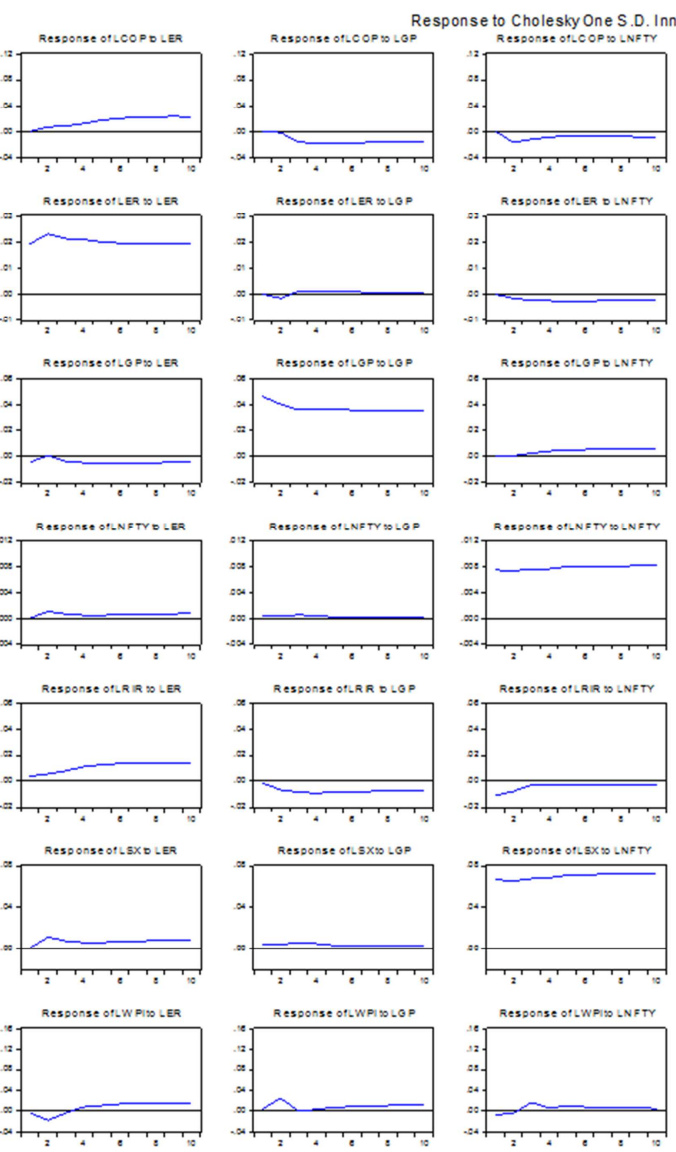
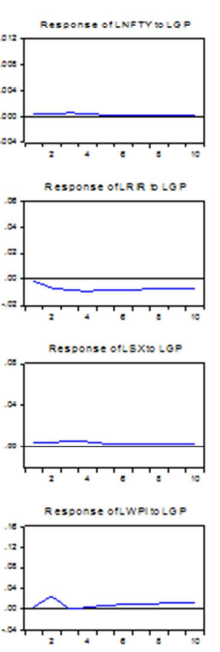
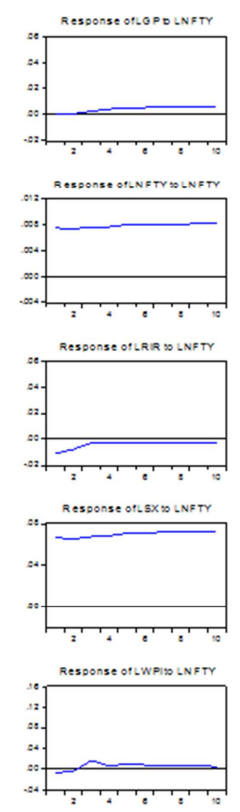
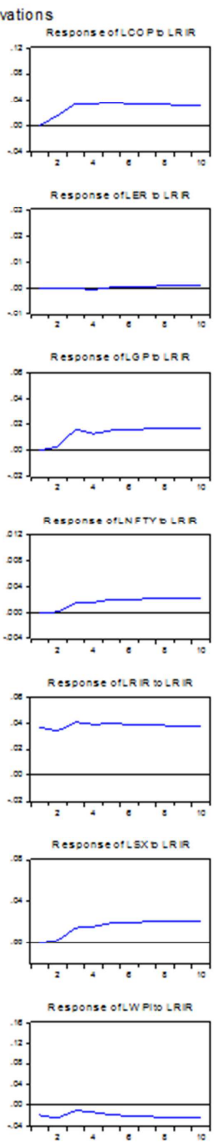
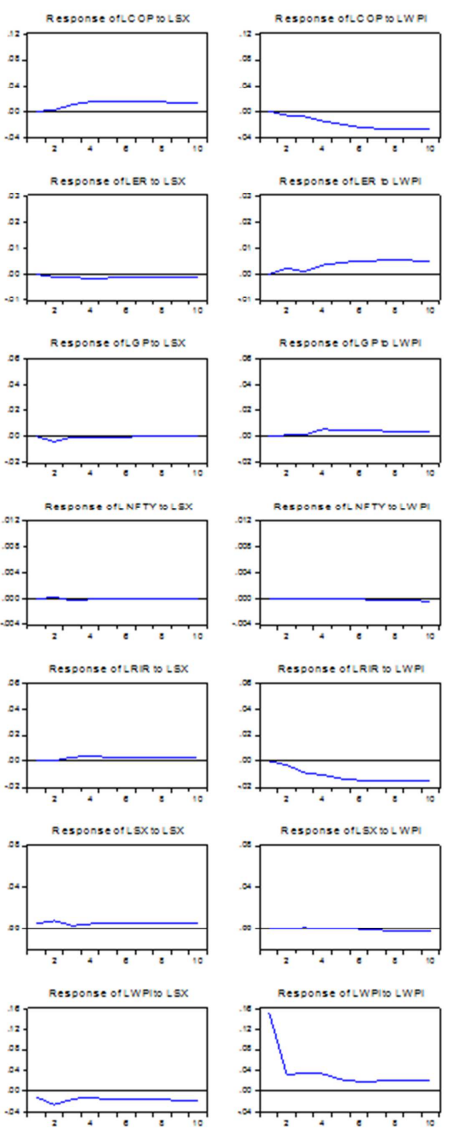

Fig. 2. Impulse Response Test Results. 
The whole model is one of insistence rather than temporary annoyance that designate a comparatively large extent of interdependence among the selected variables. The sensex and nifty reactions to shocks to crude oil price, exchanges rates, real interest rates and whole prices indices were considerably high. On the other hand, a negative shock from both sensex and nifty to real interest was found and to some extent to the wholesale price index but a positive shock from both sensex and nifty to other selected macroeconomic variables was observed.

\subsection{Variance Decomposition Test Results}

Variance decomposition test was made to examine whether there was any short-run association between macroeconomic variables and stock market. In other words, variance decomposition test was used to examine how the stock price indices responded to an unexpected change in the selected macroeconomic variables. Variance decompositions assess the percentage of the forecast error variance of each variable to be exact elucidated by its own perfection and by perfections from the other selected variables under study. There is a smaller extent of interdependence or a greater extent of independence while a series is influenced and a greater or smaller percentage of its forecast error variance can be recognized to its own perfection rather than perfections from the other selected variables (Gilmore et al, 2009). Table 8 shows that the proportions of the forecast error variance in all variables to facilitate could be elucidated by its individual improvement on the diagonal and in the course of developments from other variables (off the diagonal) at periods of 1 month, 6 months and 12 months. International crude oil price and exchange rates showed the maximum comparative liberty of their individual forecast error variance elucidated respectively at the three periods, followed by gold price, wholesale price index, real interest rates, nifty and sensex.

Table 7. Variance Decomposition Test Results.

\begin{tabular}{|c|c|c|c|c|c|c|c|}
\hline \multicolumn{8}{|c|}{ Variance Decomposition of LOP: } \\
\hline Period & LCOP & LER & LGP & LNFTY & LRIR & LSX & LWPI \\
\hline 1 & 100.0000 & 0.000000 & 0.000000 & 0.000000 & 0.000000 & 0.000000 & 0.000000 \\
\hline 2 & 96.79473 & 0.256036 & 0.020819 & 1.495021 & 1.208778 & 0.016117 & 0.208504 \\
\hline 3 & 92.23663 & 0.372365 & 0.872639 & 1.399010 & 4.441996 & 0.353691 & 0.323667 \\
\hline \multicolumn{8}{|c|}{ Variance Decomposition of LER: } \\
\hline Period & LCOP & LER & LGP & LNFTY & LRIR & LSX & LWPI \\
\hline 1 & 2.359518 & 97.64048 & 0.000000 & 0.000000 & 0.000000 & 0.000000 & 0.000000 \\
\hline 2 & 1.291771 & 97.54725 & 0.256417 & 0.247982 & 0.000172 & 0.108014 & 0.548392 \\
\hline 3 & 1.447209 & 97.08549 & 0.275191 & 0.553670 & 0.001021 & 0.199698 & 0.437720 \\
\hline \multicolumn{8}{|c|}{ Variance Decomposition of LGP: } \\
\hline Period & LCOP & LER & LGP & LNFTY & LRIR & LSX & LWPI \\
\hline 1 & 4.510168 & 0.833496 & 94.65634 & 0.000000 & 0.000000 & 0.000000 & 0.000000 \\
\hline 2 & 3.155304 & 0.490210 & 95.67410 & 0.001972 & 0.185994 & 0.466091 & 0.026326 \\
\hline 3 & 3.113883 & 0.667233 & 90.98763 & 0.092809 & 4.759600 & 0.332190 & 0.046660 \\
\hline \multicolumn{8}{|c|}{ Variance Decomposition of LNFTY: } \\
\hline Period & LCOP & LER & LGP & LNFTY & LRIR & LSX & LWPI \\
\hline 1 & 11.43469 & 0.041526 & 0.365127 & 88.15865 & 0.000000 & 0.000000 & 0.000000 \\
\hline 2 & 16.70232 & 1.137482 & 0.367272 & 81.67435 & 0.033066 & 0.084699 & 0.000809 \\
\hline 3 & 19.62706 & 0.993932 & 0.422849 & 77.77854 & 1.093041 & 0.071954 & 0.012627 \\
\hline \multicolumn{8}{|c|}{ Variance Decomposition of LRIR: } \\
\hline Period & LCOP & LER & LGP & LNFTY & LRIR & LSX & LWPI \\
\hline 1 & 5.200975 & 0.970869 & 0.157090 & 7.094081 & 86.57698 & 0.000000 & 0.000000 \\
\hline 2 & 6.543757 & 1.569041 & 1.509329 & 5.624334 & 84.48705 & 0.002572 & 0.263919 \\
\hline 3 & 7.296709 & 2.123471 & 2.271743 & 3.498933 & 82.91957 & 0.194800 & 1.694775 \\
\hline \multicolumn{8}{|c|}{ Variance Decomposition of LSX: } \\
\hline Period & LCOP & LER & LGP & LNFTY & LRIR & LSX & LWPI \\
\hline 1 & 11.29782 & 0.035138 & 0.474313 & 87.60563 & 0.002553 & 0.584545 & 0.000000 \\
\hline 2 & 16.27658 & 1.297959 & 0.439122 & 80.99572 & 0.073532 & 0.912337 & 0.004756 \\
\hline 3 & 19.13557 & 1.166434 & 0.494077 & 77.22129 & 1.320795 & 0.649052 & 0.012783 \\
\hline \multicolumn{8}{|c|}{ Variance Decomposition of LWPI: } \\
\hline Period & LCOP & LER & LGP & LNFTY & LRIR & LSX & LWPI \\
\hline 1 & 2.074470 & 0.053222 & 0.082308 & 0.172375 & 1.532735 & 0.554041 & 95.53085 \\
\hline 2 & 2.090107 & 1.139217 & 2.376187 & 0.204574 & 3.531559 & 2.909010 & 87.74935 \\
\hline 3 & 1.987649 & 1.087579 & 2.220427 & 1.204656 & 3.638174 & 3.488757 & 86.37276 \\
\hline
\end{tabular}



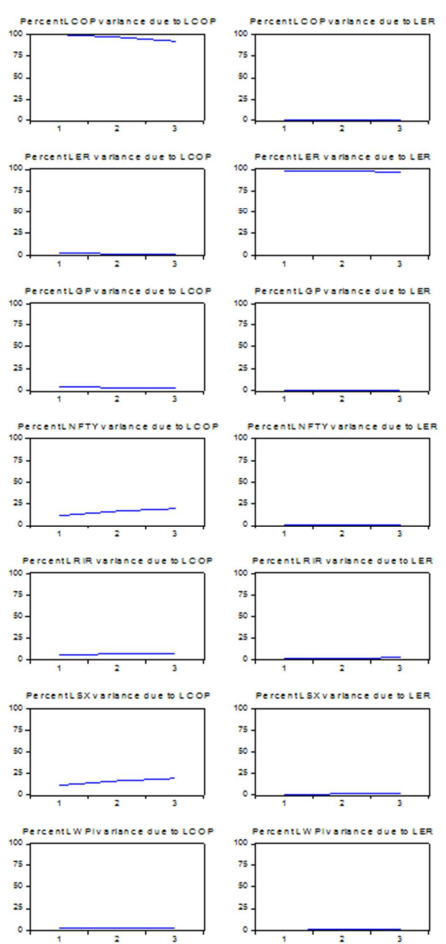
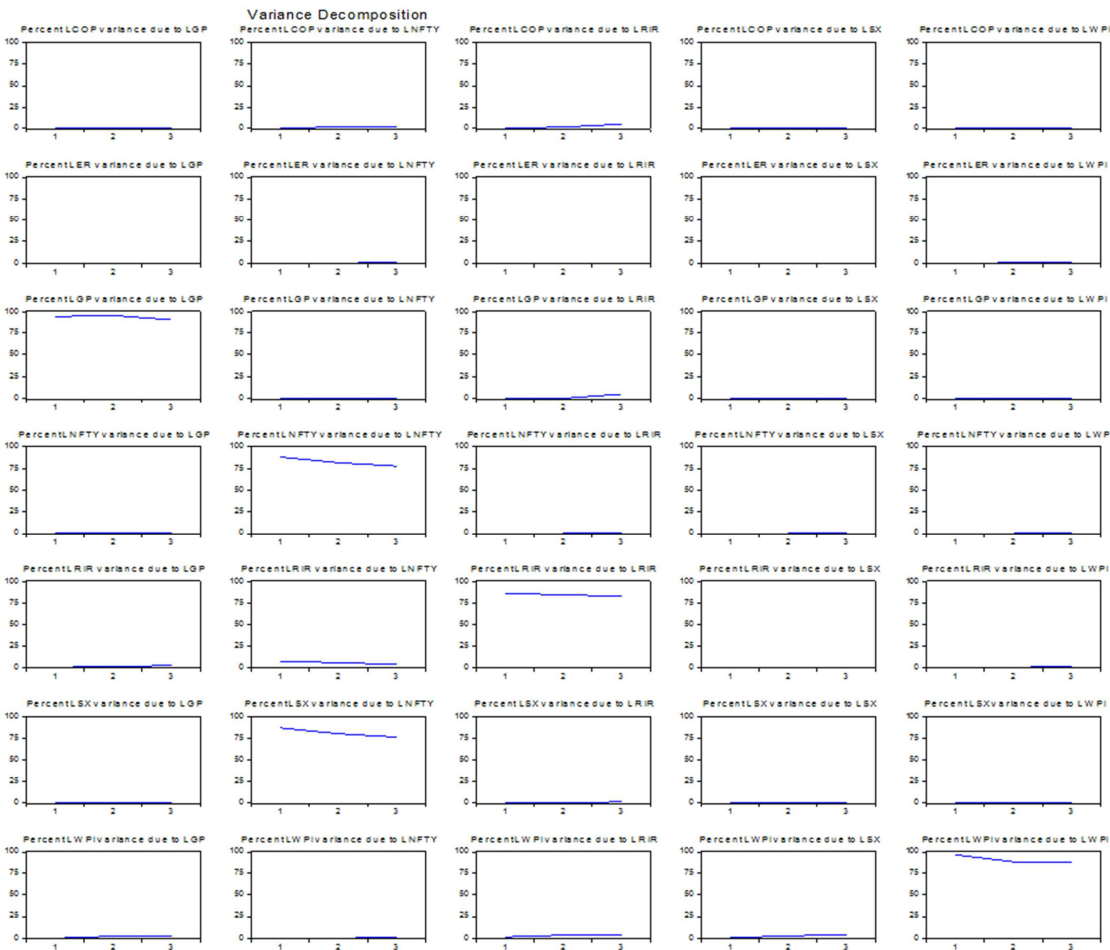

Fig. 3. Variance Decomposition Test Results

\subsection{Pairwise Causality Test Results}

Granger causality test was applied to observe whether there was any causal connection plus causation movement between selected macroeconomic indicators and two stock market indices (sensex and nifty). Table 8 illustrates the pairwise causal test results which indicate that there was no causal relationship between (i) nifty and exchange rates and (ii) sensex and exchange rates because the probability is more than 0.05 . This table also shows that there was a unidirectional causal connection between (i) nifty and crude oil price, (ii) sensex and crude oil price, (iii) nifty and gold price, (iv) sensex and gold price, (v) nifty and real interest rates, (vi) sensex and real interest rates, (vii) nifty and wholesale price index and (viii) sensex and wholesale price index because the probability was more than 0.05 in one direction and less than 0.05 in other direction. As a result, pairwise causal connection between the selected macroeconomic variables and stock market in India reflects that trend in one variable was not the responsible for trend in other variable under study. Thus, the present study may wrap up that causal connection is simply a trend of the preferred data as argued by Awe (2012).

Table 8. Pairwise causality test results (Lags: 1).

\begin{tabular}{|c|c|c|c|c|}
\hline Null Hypothesis: & Type of Causality & F-Statistic & Prob. & Decision \\
\hline LNFTY $\uparrow$ LCOP & \multirow{2}{*}{ Unidirectional causality } & 5.19766 & 0.0236 & reject $\mathrm{H}_{0}$ \\
\hline LCOP $\uparrow \mathrm{LNFTY}$ & & 3.15460 & 0.0771 & $\mathrm{DNR} \mathrm{H}_{0}$ \\
\hline $\mathrm{LSX} \uparrow \mathrm{LCOP}$ & \multirow{2}{*}{ Unidirectional causality } & 5.48380 & 0.0201 & reject $\mathrm{H}_{0}$ \\
\hline $\mathrm{LCOP} \uparrow \mathrm{LSX}$ & & 2.77965 & 0.0969 & $\mathrm{DNR} \mathrm{H}_{0}$ \\
\hline LNFTY $\uparrow$ LER & \multirow{2}{*}{ No causality } & 0.29244 & 0.5892 & $\mathrm{DNR} \mathrm{H}_{0}$ \\
\hline $\mathrm{LER} \uparrow \mathrm{LNFTY}$ & & 3.41753 & 0.0659 & $\mathrm{DNR} \mathrm{H}_{0}$ \\
\hline LSX $\uparrow \mathrm{LER}$ & No causality & 0.30777 & 0.5796 & $\mathrm{DNR} \mathrm{H}_{0}$ \\
\hline LNFTY $\uparrow$ LGP & \multirow{2}{*}{ Unidirectional causality } & 0.46059 & 0.4981 & $\mathrm{DNR} \mathrm{H}_{0}$ \\
\hline LGP $\uparrow \mathrm{LNFTY}$ & & 5.37977 & 0.0213 & reject $\mathrm{H}_{0}$ \\
\hline $\mathrm{LSX} \uparrow \mathrm{LGP}$ & \multirow{2}{*}{ Unidirectional causality } & 0.62124 & 0.4315 & $\mathrm{DNR} \mathrm{H}_{0}$ \\
\hline LGP $\uparrow \mathrm{LSX}$ & & 5.24658 & 0.0230 & reject $\mathrm{H}_{0}$ \\
\hline LRIR $\uparrow$ LNFTY & \multirow{2}{*}{ Unidirectional causality } & 3.98477 & 0.0472 & reject $\mathrm{H}_{0}$ \\
\hline LNFTY $\uparrow$ LRIR & & 2.99298 & 0.0851 & DNR $\mathrm{H}_{0}$ \\
\hline LWPI $\uparrow \mathrm{LNFTY}$ & \multirow{2}{*}{ Unidirectional causality } & 0.03337 & 0.8552 & $\mathrm{DNR} \mathrm{H}_{0}$ \\
\hline LNFTY $\uparrow \mathrm{LWPI}$ & & 9.70955 & 0.0021 & reject $\mathrm{H}_{0}$ \\
\hline LRIR $\uparrow \mathrm{LSX}$ & Unidirectional causality & 3.73568 & 0.0446 & $\mathrm{DNR} \mathrm{H}_{0}$ \\
\hline LWPI $\uparrow \mathrm{LSX}$ & \multirow{2}{*}{ Unidirectional causality } & 0.08019 & 0.7773 & $\mathrm{DNR} \mathrm{H}_{0}$ \\
\hline LSX $\uparrow \mathrm{LWPI}$ & & 10.1075 & 0.0017 & reject $\mathrm{H}_{0}$ \\
\hline
\end{tabular}

Note: Decision rule: reject $\mathrm{H}_{0}$ if $\mathrm{P}$-value $<0.05, \mathrm{DNR}=$ Do not reject; $\uparrow=$ does not Granger cause. 


\section{Conclusion}

The effect of selected macroeconomic variables shocks on the stock market of India would be survived if sensex and nifty are significantly associated with the selected macroeconomic variables during the study period. The selected time series data were stationary at $\mathrm{I}(1)$ that is a pointer of the cointegration test and causality and to find out the affiliation among all the chosen variables in the long run. The cointegration test results illustrate that unrestricted cointegration affiliation among the chosen variables in this study existed in one cointegrated vector using optimum lag length in the long-run period. It confirms that India's stock market was persuaded significantly by gold price, crude oil price, exchange rates, real interest rates and wholesale price index during the period under study. Again, there was a unidirectional causal connection between nifty and crude oil price, sensex and crude oil price, nifty and gold price, sensex and gold price, nifty and real interest rates, sensex and real interest rates, nifty and wholesale price index and sensex and wholesale price index. The impulse response functions exemplify that the sensex and nifty reactions to shocks on crude oil prices, exchanges rates, real interest rates and whole prices indices were positive while a negative shock from sensex and nifty to real interest was noticed. Variance decomposition test results indicate that international crude oil price and exchange rates reflected the maximum comparative liberty of their individual forecast error variance elucidated respectively followed by domestic gold price, wholesale price index, real interest rates, nifty and sensex. These results were not contradicted with the economic policy of India because India's stock widely fluctuated on account of less foreign investment and lack of confidence of the investors was observed on account of financial crisis.

\section{References}

[1] Abdelbaki, H. H. (2013). Causality Relationship between Macroeconomic Variables and Stock Market Development: Evidence from Bahrain. The International Journal of Business and Finance Research, 7(1), 69-84.

[2] Akash, R., Shahid, I., Hassan, A., Jahid, M. T., Shah, S. Z. A., and Khan, M. I. (2011). Cointegration and Causality Analysis of Dynamic Linkage between Economic Forces and Equity Market: An Empirical Study of Stock Returns (KSE) and Macroeconomic Variables. African Journal of Business Management, 5(27), 10940-10964.

[3] Apergis, N. and S. Eleftheriou. (2002). Interest Rates, Inflation, and Stock Prices: The Case of the Athens Stock Exchange. Journal of Policy Modeling, 24, 231-236.

[4] Barrows, C. W. and Nakat, A. (1994). Use of Macroeconomic Variables to Evaluate Selected Hospitality Stock Returns in the U.S. International Journal of Hospitality Management, 13(2), 119-128.

[5] Bhattacharya, B., and Mukherjee, J. (2002). The Nature of the Causal Relationship between Stock Market and
Macroeconomic Aggregates in India: An Empirical Analysis. Conference Volume - I, Sixth Capital Market Conference, UTI Institute of Capital Markets, Mumbai, December 2002.

[6] Bhunia, A. (2013). Relationships between Commodity Market Indicators and Stock Market Index-an Evidence of India, Academy of Contemporary Research Journal, 2(3), 126-130.

[7] Bhunia, A., and Mukhuti, S. (2013). The Impact of domestic gold price on stock price indices-An empirical study of Indian stock exchanges. University Journal of Marketing and Business Research, 2(2), 035-043.

[8] Chen, N. F., R. Roll, and S. A. Ross. (1986). Economic Forces and the Stock Market. The Journal of Business, 59(3), 383403.

[9] Cong, R. -G., Y. M. Wei, J. L. Jiao, and Y. Fan. (2008). Relationships between Oil Price Shocks and Stock Market: An Empirical Analysis from China. Energy Policy, 36, 3544-3553.

[10] Dao, P. B. and Staszewski, W. J. (2014). Stationarity based Approach for Lag Length Selection in Cointegration analysis of Lamb Wabe data. 7th European Workshop on Structural Health Monitoring, 607-614, Nantes, France. <hal-01020405> https://hal.inria.fr/hal-01020405

[11] Dickey, D.A and Fuller, W. A (1981). Likelihood Ratio Statistics for Auto-Regressive Time Series with a Unit Root. Econometrica, 49, 1057-1072.

[12] Fama, E. F. (1965). The Behavior of Stock-Market Prices. Journal of Business, 38, 34-105.

[13] Fama, E. F. (1970). Efficient Capital Markets: A Review of Theory and Empirical Work. Journal of Finance, 25(2), 383-417.

[14] Gilmore, C.G, McManus, G.M and Sharma, R (2009). The Dynamics of Gold Prices, Gold Mining Stock Prices and Stock Market Prices Comovements", Research in Applied Economics, 1(1), E2, 1-19.

[15] Gonzalo, J. (1994). A Comparison of Five Alternative Methods of Estimating Long Run Equilibrium Relationships. Journal of Econometrics, 60, 203-33.

[16] Hussin, M. Y. M, Muhammad, F, A Razak, Abdul, Tha, G P and Marwan, N (2013). The Link between Gold Price, Oil Price and Islamic Stock Market: Experience from Malaysia, Journal of Studies in Social Sciences, 4(2), 161-182.

[17] Krugman, P. (1983). Oil Shocks and Exchange Rate Dynamics. Exchange Rates and International Macroeconomics, National Bureau of Economic Research, University of Chicago Press, 259-284.

[18] Kwon, C. S. and T. S. Shin. (1999). Cointegration and Causality between Macroeconomic Variables and Stock Market Returns. Global Finance Journal, 10(1), 71-81.

[19] Luutkepohl, H., \& Saikkonen, P. (2000).Testing for the cointegrating rank of a VAR process with a time trend, Journal of Econometrics. 95, 177-198.

[20] Mishra, A. K. (2004). Stock Market and Foreign Exchange Market in India: Are They Related? South Asia Economic Journal. 5(2), 209-232.

[21] Naik, P. K. and P. Padhi. (2012). The Impact of Macroeconomic Fundamentals on Stock Prices Revisited: Evidence from Indian Data. Eurasian Journal of Business and Economics, 5(10), 25-44. 
[22] Omran, M. and J. Pointon. (2001). Does the Inflation Rate Affect the Performance of the Stock Market? The Case of Egypt. Emerging Markets Review. 2, 263-279.

[23] Osterwald-Lenum, M. (1992). A Note with Quintiles of the Asymptotic Distribution of the Maximum Likelihood Co-integration Rank Test Statistic. Oxford Bulletin of Economics and Statistics, 54, 461-472.

[24] Panda, C. (2008). Do Interest Rates Matter for Stock Markets? Economic \& Political Weekly, 26, 107-115.

[25] Patel, S. A. (2014). Causal and Co-integration Analysis of Indian and Selected Asian Stock Markets. Drishtikon: A Management Journal, 5(1), 37-52.

[26] Ross, S. A. (1976). The Arbitrage Pricing Theory of Capital Assets Pricing. Journal of Economic Theory. 13, 341-360.
[27] Sahu, T. N. and A. Gupta. (2011). Do the Macroeconomic Variables Influence the Stock Return?-An Enquiry into the Effect of Inflation. In Global Business Recession: Lessons Learnt, 1, edited by S. S. Bhakar, N. Nathani, T. Singh, and S. Bhakar. Allahabad: Crescent, 136-145.

[28] Tripathi, V., and Seth, R. (2014). Stock Market Performance and Macroeconomic Factors: The Study of Indian Equity Market. Global Business Review, 15, 291-316.

[29] Wang, M., Wang, C., and Huang, T. (2010). Relationships among Oil Price, Gold Price, Exchange Rate and International Stock Markets. International Research Journal of Finance and Economics, 47, 80-89. 